\title{
A cumulative damage model for fatigue life estimation of high-strength steels in high-cycle and very-high-cycle fatigue regimes
}

\author{
C. SUN, J. XIE, A. ZHAO, Z. LEI and Y. HONG \\ State Key Laboratory of Nonlinear Mechanics, Institute of Mechanics, Chinese Academy of Sciences, Beijing 100190, China \\ Received in final form 2 November 2011
}

A B S TRACT A cumulative fatigue damage model is presented to estimate fatigue life for high-strength steels in high-cycle and very-high-cycle fatigue regimes with fish-eye mode failure, and a simple formula is obtained. The model takes into account the inclusion size, fine granular area (FGA) size, and tensile strength of materials. Then, the 'equivalent crack growth rate' of FGA is proposed. The model is used to estimate the fatigue life and equivalent crack growth rate for a bearing steel (GCr15) of present investigation and four high-strength steels in the literature. The equivalent crack growth rate of FGA is calculated to be of the order of magnitude of $10^{-14}-10^{-11} \mathrm{~m} / \mathrm{cycle}$. The estimated results accord well with the present experimental results and prior predictions and experimental results in the literature. Moreover, the effect of inclusion size on fatigue life is discussed. It is indicated that the inclusion size has an important influence on the fatigue life, and the effect is related to the relative size of inclusion for FGA. For the inclusion size close to the FGA size, the former has a substantial effect on the fatigue life. While for the relatively large value of FGA size to inclusion size, it has little effect on the fatigue life.

Keywords crack growth rate; fatigue damage; fish-eye fracture; high-cycle fatigue; veryhigh-cycle fatigue; life estimation

\section{INTRODUCTION}

In recent years, the fatigue behaviour of metallic materials in very-high-cycle fatigue (VHCF) regime has drawn great attention ${ }^{1-6}$ because the development of modern industry often needs metal components (such as engine parts, axes, turbine disks in aerospace and railway wheels) to endure $10^{8}-10^{10}$ cyclic loadings in service ${ }^{7}$. The highcycle fatigue (HCF) and VHCF of high strength steels often presented a distinct feature of fish-eye mode failure. In the central region of fish-eye, a fine granular area $(\mathrm{FGA})^{8}$ was usually observed surrounding the inclusion of crack origin. In the literature, FGA was also called the optical dark area $(\mathrm{ODA})^{9}$ or granular-bright-facet $(\mathrm{GBF})^{10}$ or facet $(\mathrm{FCT})^{11}$. For this, Murakami et al..$^{9} 12$ presumed that the formation of FGA was caused by cyclic stress coupled with internal hydrogen trapped by non-metallic inclusion. Shiozawa et al. ${ }^{13}$ proposed a 'dispersive decohesion of spherical carbide' model for the formation of FGA. Sakai ${ }^{8}$ proposed a model to explain the formation of FGA by 'polygonization and micro-debonding'. Although the proposed formation mechanism of these models varied,

Correspondence: Y. Hong. E-mail: hongys@imech.ac.cn they have the similarity that the formation of FGA is caused by the irreversible localized deformation induced by cyclic stress.

In addition to the measurements of FGA evolution process and the understanding of FGA formation mechanism, some empirical methods are also proposed to predict the fatigue strength or fatigue life in HCF and VHCF regimes. For example, Murakami and Endo ${ }^{14}$ proposed the $\sqrt{\text { area }}$ parameter model to predict the fatigue strength of high-strength steels. Tanaka and Akiniwa ${ }^{11}$ assumed that Paris law was still suitable for FGA, and derived a crack propagation law from $S-N$ data in the VHCF regime of a bearing steel. Wang et al..$^{15}$ presented a model for predicting the fatigue life of high-strength low alloy steels by using Paris law for crack growth life and developing the dislocation model proposed by Tanaka and Mura $^{16}$ for fatigue crack initiation. Chapetti et al. ${ }^{17}$ proposed an empirical relation on FGA size, inclusion size and the number of cycles based on experimental data, and deduced an expression to estimate the internal fatigue limit for high-strength steels associated with a fatigue life of $10^{10}$ cycles. Harlow et al. ${ }^{18}$ presented a simple crack growth based probability model and used it to examine the $S-N$ response for high-strength steels. Liu et al..$^{19,20}$ 
developed a model to predict the fatigue strength at $10^{9}$ cycles of high-strength steels based on the effect of hydrogen during the FGA formation, and then proposed an expression in form of Basquin equation for the prediction of $S-N$ curves based on the prediction of fatigue strengths at $10^{6}$ cycles and at $10^{9}$ cycles.

Many pieces of research have shown that the fatigue life for VHCF regime is primarily due to the initiation period of fatigue crack, and more than $90 \%$ of fatigue life may be consumed to form FGA. ${ }^{11,13,15,21,22}$ According to the results by Murakami et al. ${ }^{9}$, the crack growth rate was much less than $10^{-11} \mathrm{~m} /$ cycle in the early stage of the VHCF process, and one could not assume that crack growth occurred cycle by cycle. Tanaka and Akiniwa ${ }^{11}$ also indicated that the crack propagation rate in the facet region of a bearing steel in VHCF was smaller than $10^{-12}$ $\mathrm{m} /$ cycle. The length $10^{-12} \mathrm{~m}$ is far below the Burgers vector, and the classical dislocation mechanism of crack propagation is not applicable for the facet region. Hence, it is very essential to develop a model for estimating the fatigue life of FGA in order to predict reasonably the fatigue life of mechanical components.

Fatigue is a process of damage accumulation cycle by cycle in a material undergoing cyclic stresses and strains, and fatigue damage is fundamentally a result of material structural changes at the microscopic level. ${ }^{23}$ So for fisheye mode failure observed, it is reasonable to believe that the microscopic parameters (such as inclusion size and FGA size) at the fracture origin have an inherent relationship with the macroscopic quantities (tensile strength and applied stress level) based on the continuum mechanics concepts.

Motivated by these considerations, a model is presented in this paper for estimating the fatigue life of highstrength steels in HCF and VHCF regimes with fish-eye mode failure from the view of cumulative fatigue damage. Then, the equivalent crack growth rate of FGA is proposed, and an approximate analytical expression is derived. The effect of inclusion size is also discussed. The results are compared with present experimental results and previous predictions and experimental results in the literature.

\section{EXPERIMENTAL PROCEDURE}

\section{Testing material and specimen}

The material used in the present paper is a high carbon chromium bearing steel (GCr15), and the main chemical compositions are $1.01 \mathrm{C}, 1.45 \mathrm{Cr}, 0.35 \mathrm{Mn}$ and $0.28 \mathrm{Si}$ in mass percentage (Fe balance). The geometries of specimens are shown in Fig. 1. Specimens were heated at $845^{\circ} \mathrm{C}$ for $2 \mathrm{~h}$ in vacuum, then oil-quenched and tempered for $2.5 \mathrm{~h}$ in vacuum at $300^{\circ} \mathrm{C}$ with furnace-cooling.

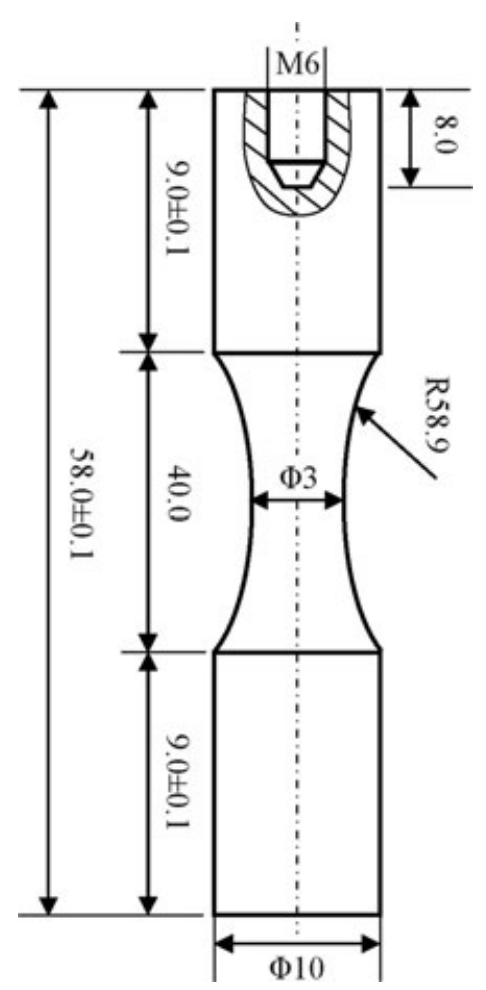

Fig. 1 Geometries of specimens, dimensions in $\mathrm{mm}$.

The tensile strength of specimens is $2150 \mathrm{MPa}$, and the Vickers hardness is $741 \mathrm{kgf} / \mathrm{mm}^{2}$. Before fatigue testing, the round notch surface was ground and finally polished to eliminate machine scratches.

\section{Testing methods}

The fatigue tests were conducted on a Shimadzu USF2000 at a resonance frequency of $20 \mathrm{kHz}$ at room temperature in air with a resonance interval of $100 \mathrm{~ms}$ per $500 \mathrm{~ms}$ and the stress ratio $R=-1$. Compressive cold air was used to cool the specimens during ultrasonic fatigue testing. The fracture surfaces of all failed specimens were observed and the parameters of crack origin (sizes of inclusions and FGA surrounding inclusions) were measured by a field-emission type scanning electron microscope.

\section{EXPERIMENTAL RESULTS}

Almost all of the specimens fail from the internal inclusion with a fish-eye pattern, as illustrated in Fig. 2. The fatigue testing data and the measurements of related inclusion and FGA sizes observed from fracture surfaces are listed in Table 1 . It is seen from Table 1 that the 

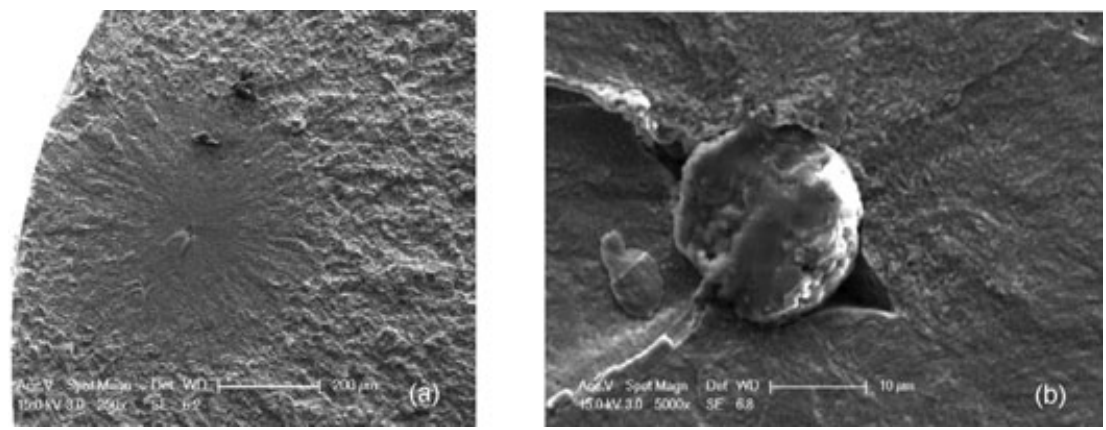

Fig. 2 Morphology of fracture surface for a broken specimen with a fish-eye pattern, $\sigma=1008 \mathrm{MPa}, N_{f}=3.50 \times 10^{6}$. (a) Low resolution for fracture surface with fish-eye. (b) High resolution for FGA surrounding inclusion in the centre of fish-eye.

Table 1 Fatigue testing data and the data of fracture origins measured from fracture surfaces.

\begin{tabular}{|c|c|c|c|c|}
\hline Specimen number & $\sigma(\mathrm{MPa})$ & $\sqrt{\operatorname{area} \operatorname{In}}(\mu \mathrm{m})$ & $\sqrt{\operatorname{are} a_{\mathrm{FGA}}}(\mu \mathrm{m})$ & Fatigue life \\
\hline 1 & 1148 & 16.82 & 28.41 & $5.75 \times 10^{5}$ \\
\hline 2 & 1100 & 22.96 & 33.99 & $5.25 \times 10^{5}$ \\
\hline 3 & 1074 & 20.35 & 32.76 & $1.08 \times 10^{6}$ \\
\hline 4 & 1023 & 32.74 & 40.56 & $1.05 \times 10^{6}$ \\
\hline 5 & 1008 & 18.49 & 30.68 & $3.50 \times 10^{6}$ \\
\hline 6 & 1000 & 28.60 & 41.48 & $8.18 \times 10^{5}$ \\
\hline 7 & 998 & 23.60 & 41.19 & $1.09 \times 10^{7}$ \\
\hline 8 & 994 & 22.38 & 37.79 & $5.35 \times 10^{6}$ \\
\hline 9 & 988 & 23.75 & 32.63 & $9.40 \times 10^{8}$ \\
\hline 10 & 986 & 26.06 & 33.69 & $2.19 \times 10^{6}$ \\
\hline 11 & 978 & 22.69 & 30.51 & $4.27 \times 10^{7}$ \\
\hline 12 & 960 & 37.80 & 45.16 & $2.04 \times 10^{7}$ \\
\hline 13 & 938 & 25.51 & 40.22 & $4.25 \times 10^{6}$ \\
\hline
\end{tabular}

fatigue life is not only dependent on the stress amplitude, but also on the inclusion size and the FGA size, and the fatigue life may abnormally decrease with decreasing stress amplitude. This indicates that the inclusion size and the FGA size at fracture origin have substantial influence on the fatigue life of specimens with fish-eye mode failure. So the model to be developed for estimating the fatigue life of high-strength steels with fish-eye mode failure should include the inclusion size and FGA size.

For the clarity of the relation between the stress amplitude and the FGA size at the fracture origin, Fig. 3 shows the stress intensity factor range at the front of FGA $\Delta K_{\mathrm{FGA}}$ versus the stress amplitude for the experimental results, where $\Delta K_{\mathrm{FGA}}$ is calculated by $\Delta K_{\mathrm{FGA}}=$ $0.5 \sigma_{a} \sqrt{\pi \sqrt{\text { area }_{\mathrm{FGA}}}}, 24$ with $\sigma_{a}$ being the stress amplitude under the consideration that this expression is commonly accepted in relevant cases ${ }^{8,10,11,25,26}$. It is seen from Fig. 3 that the variation of $\Delta K_{\mathrm{FGA}}$ with the stress amplitude is very small and the values keep almost a constant, i.e. $\Delta K_{\mathrm{FGA}}$ is regardless of the stress amplitude, the fatigue life and the FGA size. In other words, $\Delta K_{\mathrm{FGA}}$ reflects the propensity of high-strength material. The result is in

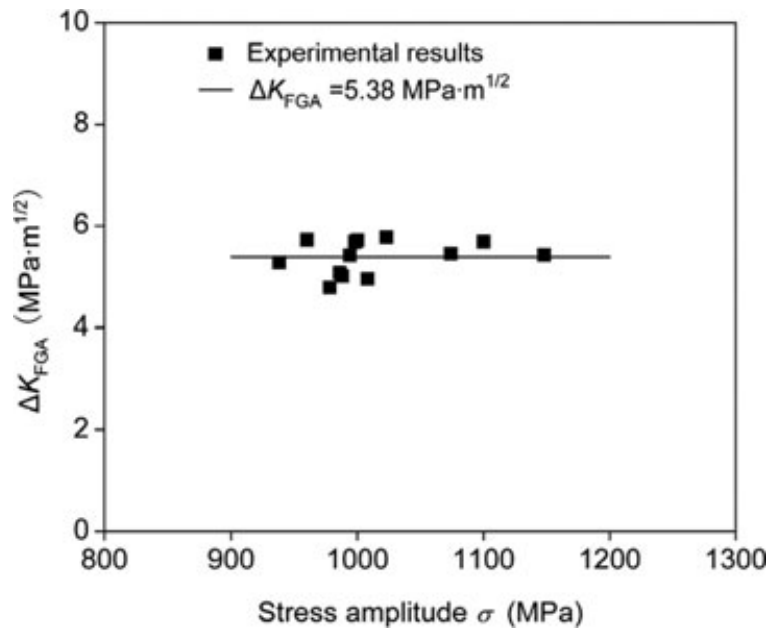

Fig. 3 Stress intensity factor range at the front of FGA $\Delta \mathrm{k}_{\mathrm{FGA}}$ versus stress amplitude.

accordance with those for a high carbon chromium steel (SUJ2) in the literature, ${ }^{8,25}$ which shows that $\Delta K_{\mathrm{FGA}}$ corresponds to the threshold value of the crack propagation $\Delta K_{\text {th }}$. 


\section{MODEL AND ANALYSIS}

The premise of the model is that a fish-eye mode failure presents for high-strength steels in HCF and VHCF regimes, and an FGA appears surrounding the inclusion at the fracture origin. According to the cumulative fatigue damage theory, the fatigue life $N_{f}$ of FGA is the minimum of integer $N$ that satisfies

area $_{\mathrm{In}}+\sum_{n=1}^{N} S_{n} \geq$ area $_{\mathrm{FGA}}$

where $a r e a_{\mathrm{In}}$ is the inclusion projection area, $a r e a_{\mathrm{FGA}}$ is FGA, and $S_{n}(n=1,2, \ldots, N)$ is the irreversible fatigue damage projection area occurring surrounding the inclusion at crack initiation region due to the $n$th cycle.

Equation (1) can be expressed as

$\operatorname{area}_{N}=\operatorname{area}_{\mathrm{In}} \prod_{n=1}^{N}\left(1+p_{n}\right) \geq \operatorname{area}_{\mathrm{FGA}}$

where $p_{n}=S_{n} /$ area $_{n-1}$, and area $_{n}$ is the total area of irreversible fatigue damage after $n$ cycles, with area $_{0}=$ area $_{\text {In }}$, and $n=1,2, \ldots, N$.

Note that $1+p=\left[\prod_{n=1}^{N}\left(1+p_{n}\right)\right]^{1 / N}$; thus Eq. (2) is changed to the following form:

$\operatorname{area}_{\mathrm{In}}(1+p)^{N} \geq \operatorname{area}_{\mathrm{FGA}}$.

From Eq. (3), the fatigue life $N_{f}$ contributed by FGA is solved approximately as

$N_{f} \approx \frac{1}{\log (1+p)} \log \frac{\text { area }_{\mathrm{FGA}}}{\text { area }_{\mathrm{In}}}$.

It can be deduced that the value of $p$ is much smaller than unity because of the large value of the fatigue life in HCF and VHCF regimes. Taking the Taylor series expansion for $\log (1+p)$ in Eq. (4), we have

$N_{f} \approx \frac{1}{p} \log \frac{\operatorname{area}_{\mathrm{FGA}}}{\text { area }_{\mathrm{In}}}$.

Equation (5) shows the relation among the fatigue life $N_{f}$, the inclusion projection area $a r e a_{\mathrm{In}}$, the FGA area $_{\mathrm{FGA}}$ and the parameter $p$.

As known, the traditional fatigue limit of materials is usually proportional to the tensile strength in a wide range of the strength level, ${ }^{8}$ and the applied stress level is one of the uppermost factors influencing the fatigue life. Therefore, it is reasonable to consider that the parameter $p$ is related to the applied stress level $\sigma$ and the tensile strength $\sigma_{\mathrm{b}}$ of materials. For the validation of this supposition, Fig. 4 plots the comparison of experimental values of $\log _{10} N_{f}-\log _{10} \log \left(\right.$ area $_{\mathrm{FGA}} /$ area $\left._{\mathrm{In}}\right)$ as a function of the normalized stress $\sigma_{\mathrm{b}} / \sigma$ with the fitting results for the present experimental results and the ones in the literature. From Fig. 4, the relation between $\log _{10} N_{f}-\log _{10} \log \left(\right.$ are $a_{\mathrm{FGA}} /$ are $\left._{\mathrm{In}}\right)$ and $\sigma_{\mathrm{b}} / \sigma$ can be well approximated by a linear relation. With regard to Eq. (5), the value of $p$ is obtained. Thus, it is thought that the expression of fatigue life can be written in the following form

$N_{f}=10^{\alpha \frac{\sigma_{\mathrm{b}}}{\sigma}} \log \frac{\operatorname{area}_{\mathrm{FGA}}}{\text { area }_{\mathrm{In}}}$

where $\alpha$ is readily obtained by fitting the experimental data.

It is noted that the total fatigue life is assumed to be consumed to form FGA in the present paper and that the experimental data are used in Fig. 4b retrieved from the figures in the literature. For the clarity, the related experimental data associated with the specimens in Figs. 4b-e are represented in Tables $2 \& 3$, and the specimens are rearranged in numbers in terms of stress amplitude.

\section{FGA size}

The present experimental data and several previous researches ${ }^{8,25}$ have already indicated that $\Delta K_{\mathrm{FGA}}$ is regardless of the stress amplitude and keeps almost a constant. Therefore, it is supposed that the FGA size can be obtained by the value of $\Delta K_{\mathrm{FGA}}$ and the stress amplitude for $\mathrm{HCF}$ and VHCF of high-strength steels. Figure 5 shows the value of $\Delta K_{\mathrm{FGA}}$ versus the stress amplitude for the experimental results shown in Tables $2 \& 3$. It is seen that, the variation of $\Delta K_{\mathrm{FGA}}$ with the stress amplitude is very small, which keeps almost a constant. This result further indicates that the FGA size can be obtained by the stress intensity factor range at the front of FGA and the stress amplitude for HCF and VHCF of high-strength steels. In addition, for high-strength steels, the value of the 'critical crack length' at which short crack behaviour prevails is in the order of $10 \mu \mathrm{m} .{ }^{30}$ The FGA size for high-strength steels in the present paper (almost $20-45 \mu \mathrm{m}$ ) is several times larger than $10 \mu \mathrm{m}$, so it seems that $\Delta K_{\mathrm{FGA}}$ being a constant of the present case is in accordance with the crack length larger than the 'critical size' beyond which long crack behaviour begins.

\section{Inclusion size}

The inclusion size can be obtained by experimental observation and statistical method. In the present model, the average inclusion size is used for fatigue life estimation. For example, the average inclusion size is $24.75 \mu \mathrm{m}$ for the present specimens in Table 1 .

From the above analysis, if $a_{n}$ is defined as $a_{n}=\sqrt{\text { area }}$ $(n=0,1, \ldots, N)$, one can define the 'equivalent crack growth rate' at the $n$th cycle for FGA as $a_{n}-a_{n-1}$ (meter per cycle). Further, if it is assumed that $1+p_{n}=1+p$ $(n=1,2, \ldots, N)$, an analytical formula is obtained for 

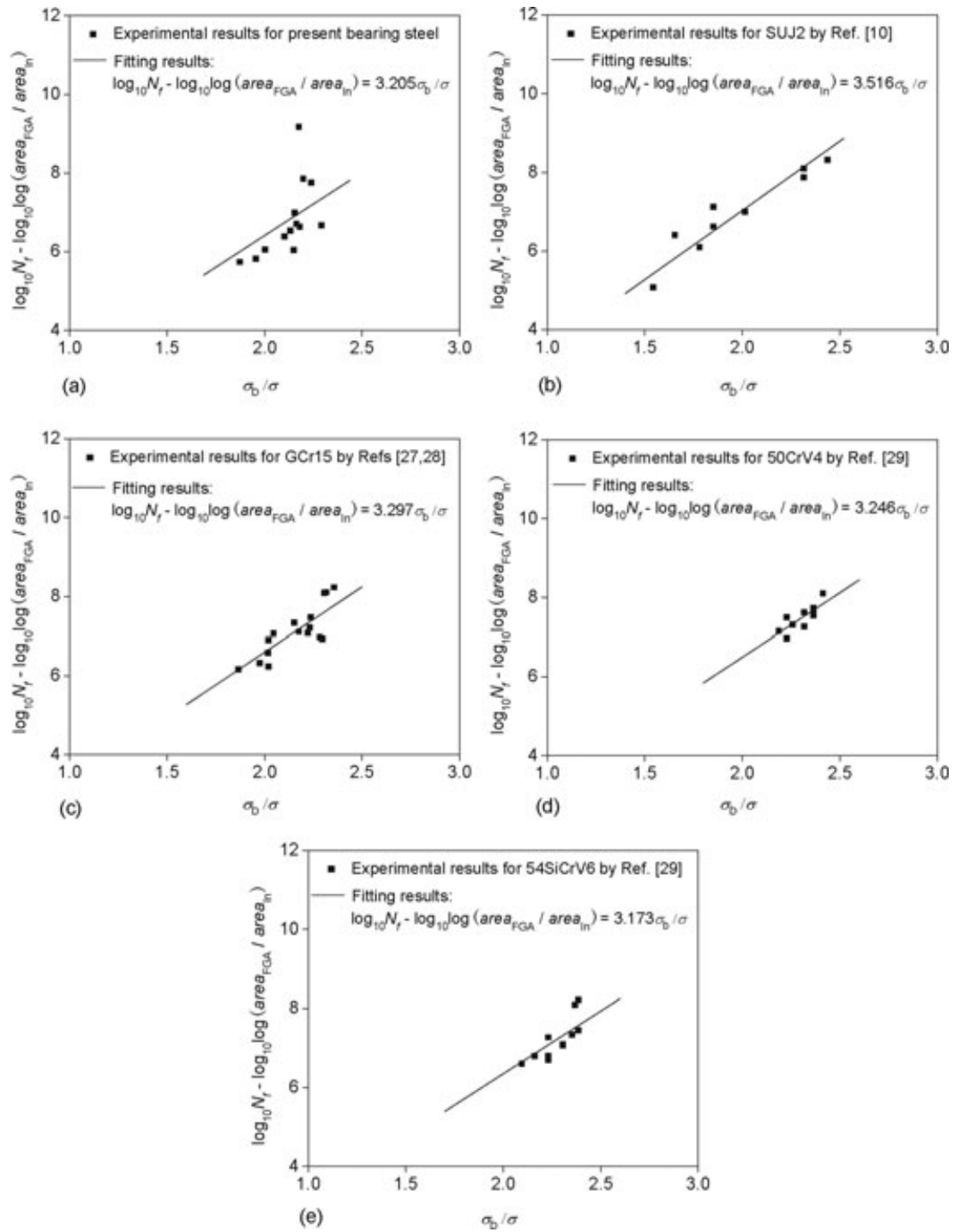

Fig. 4 Comparison of experimental values of $\log _{10} N_{f}-\log _{10} \log \left(\operatorname{area} \mathrm{FGA}_{\mathrm{A}} / \mathrm{area}_{\mathrm{In}}\right)$ as a function of normalized stress $\sigma_{\mathrm{b}} / \sigma$ with fitting results.

the equivalent crack growth rate, i.e.

$\frac{\mathrm{d} a_{n}}{\mathrm{~d} n}=\frac{\log (1+p)}{2} a_{n}$.

Substitution of $p=10^{-\alpha \frac{\sigma_{\mathrm{b}}}{\sigma}}$ into Eq. (7) leads to

$\frac{\mathrm{d} a_{n}}{\mathrm{~d} n} \approx \frac{1}{2} 10^{-\alpha \frac{\sigma_{\mathrm{b}}}{\sigma}} a_{n}$.

\section{DISCUSSION}

\section{Fatigue life estimation}

Figure 6 shows the comparison of the fatigue life estimated by the present model with the present experimental results and the ones available in the literature. The solid line denotes the fatigue life estimated by the present model with average inclusion size, the dashed line denotes the one estimated with minimum inclusion size, and the dotted line denotes the one estimated with the maximum inclusion size. It is seen from Fig. 6 that the fatigue life estimated with the minimum inclusion size is generally higher than the experimental results, while the fatigue life estimated with the maximum inclusion size is generally smaller than the experimental results, namely that most experimental datum points are within the range from the estimated values with the maximum inclusion size to the estimated ones with the minimum inclusion size. The fatigue life estimated with average inclusion size is reasonably in good agreement with the experimental results, the relative error of which is within an order of magnitude 
Table 2 Related experimental data associated with Fig. 4b by Ref. [10] and Fig. 4c by Refs [27, 28]

\begin{tabular}{|c|c|c|c|c|c|c|c|c|c|}
\hline \multicolumn{5}{|c|}{ SUJ2 by Ref. [10] } & \multicolumn{5}{|c|}{ GCr15 by Refs $[27,28]$} \\
\hline $\begin{array}{l}\text { Specimen } \\
\text { number }\end{array}$ & $\begin{array}{l}\sigma \\
(\mathrm{MPa})\end{array}$ & $\begin{array}{l}\sqrt{\operatorname{area}_{\mathrm{In}}} \\
(\mu \mathrm{m})\end{array}$ & $\begin{array}{l}\sqrt{a r e a_{\mathrm{FGA}}} \\
(\mu \mathrm{m})\end{array}$ & $\begin{array}{l}\text { Fatigue } \\
\text { life }\end{array}$ & $\begin{array}{l}\text { Specimen } \\
\text { number }\end{array}$ & $\begin{array}{l}\sigma \\
(\mathrm{MPa})\end{array}$ & $\begin{array}{l}\sqrt{\operatorname{area}_{\mathrm{In}}} \\
(\mu \mathrm{m})\end{array}$ & $\begin{array}{l}\sqrt{a r e a_{\mathrm{FGA}}} \\
(\mu \mathrm{m})\end{array}$ & $\begin{array}{l}\text { Fatigue } \\
\text { life }\end{array}$ \\
\hline 1 & 1500 & 10.11 & 18.84 & $1.50 \times 10^{5}$ & 1 & 1272 & 21.12 & 39.46 & $1.82 \times 10^{6}$ \\
\hline 2 & 1400 & 7.27 & 18.49 & $4.80 \times 10^{6}$ & 2 & 1201 & 10.44 & 20.47 & $2.83 \times 10^{6}$ \\
\hline 3 & 1300 & 9.21 & 20.57 & $2.02 \times 10^{6}$ & 3 & 1176 & 22.61 & 46.78 & $5.55 \times 10^{6}$ \\
\hline 4 & 1250 & 7.98 & 16.42 & $6.07 \times 10^{6}$ & 4 & 1174 & 14.32 & 24.70 & $1.90 \times 10^{6}$ \\
\hline 5 & 1250 & 7.09 & 18.15 & $2.47 \times 10^{7}$ & 5 & 1174 & 9.43 & 26.29 & $1.63 \times 10^{7}$ \\
\hline 6 & 1150 & 8.33 & 25.41 & $2.25 \times 10^{7}$ & 6 & 1159 & 16.12 & 27.07 & $1.21 \times 10^{7}$ \\
\hline 7 & 1000 & 10.99 & 27.31 & $1.37 \times 10^{8}$ & 7 & 1102 & 20.83 & 34.96 & $2.23 \times 10^{7}$ \\
\hline 8 & 1000 & 6.56 & 20.23 & $2.82 \times 10^{8}$ & 8 & 1090 & 19.00 & 35.26 & $1.58 \times 10^{7}$ \\
\hline \multirow[t]{8}{*}{9} & 950 & 8.69 & 40.27 & $6.41 \times 10^{8}$ & 9 & 1068 & 14.46 & 29.85 & $1.72 \times 10^{7}$ \\
\hline & & & & & 10 & 1063 & 19.26 & 33.48 & $1.81 \times 10^{7}$ \\
\hline & & & & & 11 & 1060 & 17.44 & 46.22 & $5.76 \times 10^{7}$ \\
\hline & & & & & 12 & 1039 & 15.87 & 40.71 & $1.75 \times 10^{7}$ \\
\hline & & & & & 13 & 1033 & 17.58 & 37.92 & $1.29 \times 10^{7}$ \\
\hline & & & & & 14 & 1028 & 12.69 & 31.94 & $2.25 \times 10^{8}$ \\
\hline & & & & & 15 & 1024 & 11.31 & 44.27 & $3.47 \times 10^{8}$ \\
\hline & & & & & 16 & 1007 & 16.76 & 43.45 & $3.24 \times 10^{8}$ \\
\hline
\end{tabular}

Table 3 Related experimental data associated with Figs. 4d and e by Ref. [29]

\begin{tabular}{|c|c|c|c|c|c|c|c|c|c|}
\hline \multicolumn{5}{|l|}{$50 \mathrm{CrV} 4$} & \multicolumn{5}{|l|}{ 54SiCrV6 } \\
\hline $\begin{array}{l}\text { Specimen } \\
\text { number }\end{array}$ & $\begin{array}{l}\sigma \\
(\mathrm{MPa})\end{array}$ & $\begin{array}{l}\sqrt{\text { area } \mathrm{In}} \\
(\mu \mathrm{m})\end{array}$ & $\begin{array}{l}\sqrt{\operatorname{area_{\mathrm {FGA}}}} \\
(\mu \mathrm{m})\end{array}$ & $\begin{array}{l}\text { Fatigue } \\
\text { life }\end{array}$ & $\begin{array}{l}\text { Specimen } \\
\text { number }\end{array}$ & $\begin{array}{l}\sigma \\
(\mathrm{MPa})\end{array}$ & $\begin{array}{l}\sqrt{\operatorname{area}_{\mathrm{In}}} \\
(\mu \mathrm{m})\end{array}$ & $\begin{array}{l}\sqrt{\operatorname{area}_{\mathrm{FGA}}} \\
(\mu \mathrm{m})\end{array}$ & $\begin{array}{l}\text { Fatigue } \\
\text { life }\end{array}$ \\
\hline 1 & 800 & 3.28 & 33.58 & $6.56 \times 10^{7}$ & 1 & 825 & 6.73 & 30.83 & $1.24 \times 10^{7}$ \\
\hline 2 & 785 & 5.05 & 34.64 & $3.57 \times 10^{7}$ & 2 & 800 & 4.70 & 33.58 & $2.47 \times 10^{7}$ \\
\hline 3 & 785 & 3.99 & 33.31 & $1.32 \times 10^{8}$ & 3 & 775 & 5.76 & 34.64 & $2.24 \times 10^{7}$ \\
\hline 4 & 775 & 6.91 & 35.44 & $6.69 \times 10^{7}$ & 4 & 775 & 6.02 & 35.44 & $1.77 \times 10^{7}$ \\
\hline 5 & 755 & 4.70 & 38.19 & $1.72 \times 10^{8}$ & 5 & 775 & 4.61 & 34.82 & $7.56 \times 10^{7}$ \\
\hline 6 & 755 & 3.28 & 38.10 & $8.98 \times 10^{7}$ & 6 & 750 & 6.47 & 38.72 & $4.21 \times 10^{7}$ \\
\hline 7 & 740 & 4.61 & 38.19 & $1.48 \times 10^{8}$ & 7 & 750 & 7.44 & 37.03 & $4.04 \times 10^{7}$ \\
\hline 8 & 740 & 3.01 & 39.78 & $2.23 \times 10^{8}$ & 8 & 735 & 5.14 & 39.96 & $8.81 \times 10^{7}$ \\
\hline 9 & 740 & 7.89 & 39.78 & $1.74 \times 10^{8}$ & 9 & 730 & 7.18 & 40.76 & $4.24 \times 10^{8}$ \\
\hline \multirow[t]{2}{*}{10} & 725 & 3.28 & 40.76 & $6.36 \times 10^{8}$ & 10 & 725 & 4.25 & 39.34 & $7.31 \times 10^{8}$ \\
\hline & & & & & 11 & 725 & 9.30 & 40.67 & $8.23 \times 10^{7}$ \\
\hline
\end{tabular}

except for one datum point in Fig. 6a. The reason why the experimental fatigue life for this datum point (specimen 9 in Table 1) is 2 orders of magnitude larger than the ones for the specimens (specimens 8 and 10 in Table 1) with almost the same stress level and the same inclusion size and FGA size is not very clear. As is known, the factors influencing the fatigue life is very complicated, e.g. the microstructure inhomogeneity of specimen may cause large scatter of fatigue life, which may lead to the error of the fatigue life estimation.

The effect of fatigue strength on fatigue life is also illustrated in Fig. 6, showing that the fatigue strength is the major factor influencing the fatigue life. Except for one experimental datum point in Fig. 6a, all the experimental datum points are within the range of plus and minus $10 \%$ of fatigue strength. This indicates that the present model with average inclusion size in specimens can be used to estimate the fatigue strength of high-strength steels in $\mathrm{HCF}$ and VHCF regimes, the relative error of which is within approximately $10 \%$.

It is noted that, for the samples with inclusion size bigger than the estimated FGA size under a certain stress level, the present model is not applicable, and the related results are not included in the figure. It is also noted that the shape of $S-N$ curve for high-strength steels often presents a duplex pattern corresponding to surfaceinitiated fracture mode and interior-initiated mode. ${ }^{8,10,26}$ In this study, we only consider the interior-initiated mode with FGA surrounding the inclusion at fracture origin. 

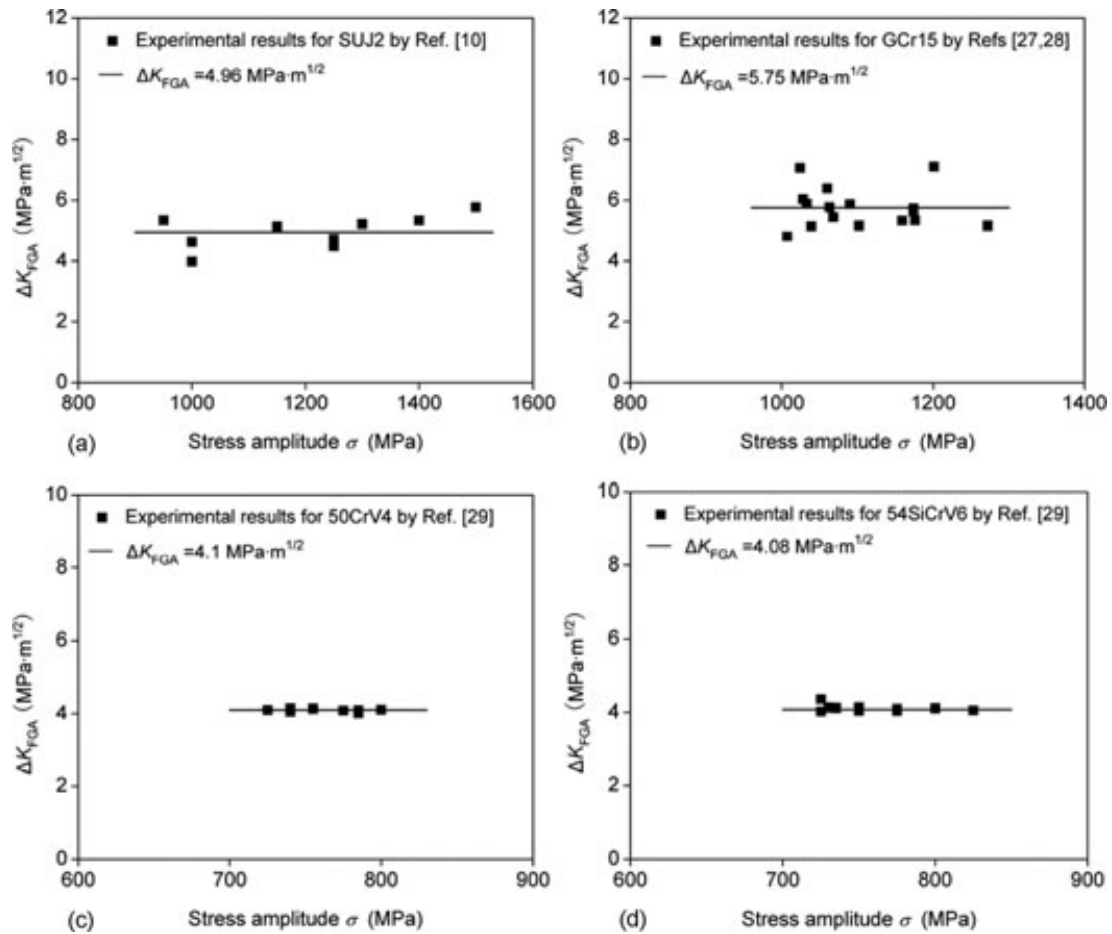

Fig. 5 Stress intensity factor range at the front of FGA $\Delta K_{\mathrm{FGA}}$ versus stress amplitude for experimental results.

\section{Estimation of equivalent crack growth rate}

Tables 4 and 5 show the relations of equivalent crack growth rate obtained from Eq. (8) versus the ratio $n / N_{f}$ for the present bearing steel (GCr15) in Table 1 and for SUJ2 by Ref. [10] in Table 2, respectively. It is seen from Tables $4 \& 5$ that the equivalent crack growth rate of FGA is dependent on the stress amplitude and loading cycle. It is in the order of magnitude $10^{-13}$ to $10^{-11} \mathrm{~m} /$ cycle for the present bearing steel (GCr15) with the stress amplitude ranging from $938 \mathrm{MPa}$ to $1148 \mathrm{MPa}$, and is in the order of magnitude $10^{-14}$ to $10^{-11} \mathrm{~m} /$ cycle for SUJ2 by Ref. [10] with the stress amplitude ranging from $950 \mathrm{MPa}$ to 1500 $\mathrm{MPa}$. The equivalent crack growth rates for the specimens by Refs [27, 28] in Table 2 and by Ref. [29] in Table 3 are also worked out, which are in the order of magnitude $10^{-13}-10^{-12} \mathrm{~m} /$ cycle for GCr 15 with the stress amplitude ranging from $1007 \mathrm{MPa}$ to $1272 \mathrm{MPa}$, and in the order of magnitude $10^{-14}-10^{-12} \mathrm{~m} /$ cycle for $50 \mathrm{CrV} 4$ with the stress amplitude ranging from $725 \mathrm{MPa}$ to $800 \mathrm{MPa}$ and for $54 \mathrm{SiCrV} 6$ with the stress amplitude ranging from 725 $\mathrm{MPa}$ to $825 \mathrm{MPa}$. These results accord well with the crack propagation rate lower than $10^{-12} \mathrm{~m} /$ cycle in the facet region of a bearing steel (SUJ2) obtained by Tanaka and Akiniwa ${ }^{11}$ and with the crack growth rate lower than $10^{-11}$ $\mathrm{m} /$ cycle in FGA of a bearing steel (GCr15) obtained by Li et $a l^{26}$. The result by Murakami $e t$ al. ${ }^{9}$ also showed that the crack growth rate was much less than $10^{-11} \mathrm{~m} /$ cycle in the early stage of the VHCF process, and one could not assume the crack growth occurred cycle by cycle. This is the reason we call it 'equivalent crack growth rate' rather than crack growth rate of FGA in this paper. Tables 4 and 5 also indicate that the equivalent crack growth rate of FGA increases with increasing inclusion size, stress amplitude and loading cycle.

\section{Effect of the inclusion size}

Figure 7 shows the variation of the dimensionless fatigue life with the ratio $\sqrt{\operatorname{area}_{\mathrm{FGA}}} / \sqrt{\operatorname{area} a_{\mathrm{In}}}$, indicating that the fatigue life increases with increasing relative size of FGA for inclusion. ${ }^{12}$ The effect of the inclusion size on the fatigue life is not only dependent on the inclusion size itself, but also on the relative size of inclusion for FGA. For the inclusion size close to the FGA size, the variation of inclusion size has a substantial effect on the fatigue life. While for the relative large value of FGA size to inclusion size, the variation of inclusion size has little effect on the fatigue life. This result indicates that it is a valid method to prolong the fatigue life of mechanical components by decreasing the inclusion size when the inclusion size is near to the FGA size, while decreasing the inclusion size for the inclusion size much smaller than the FGA size is of little help for the mechanical components enduring longer fatigue life. Figure 7 also indicates that the 

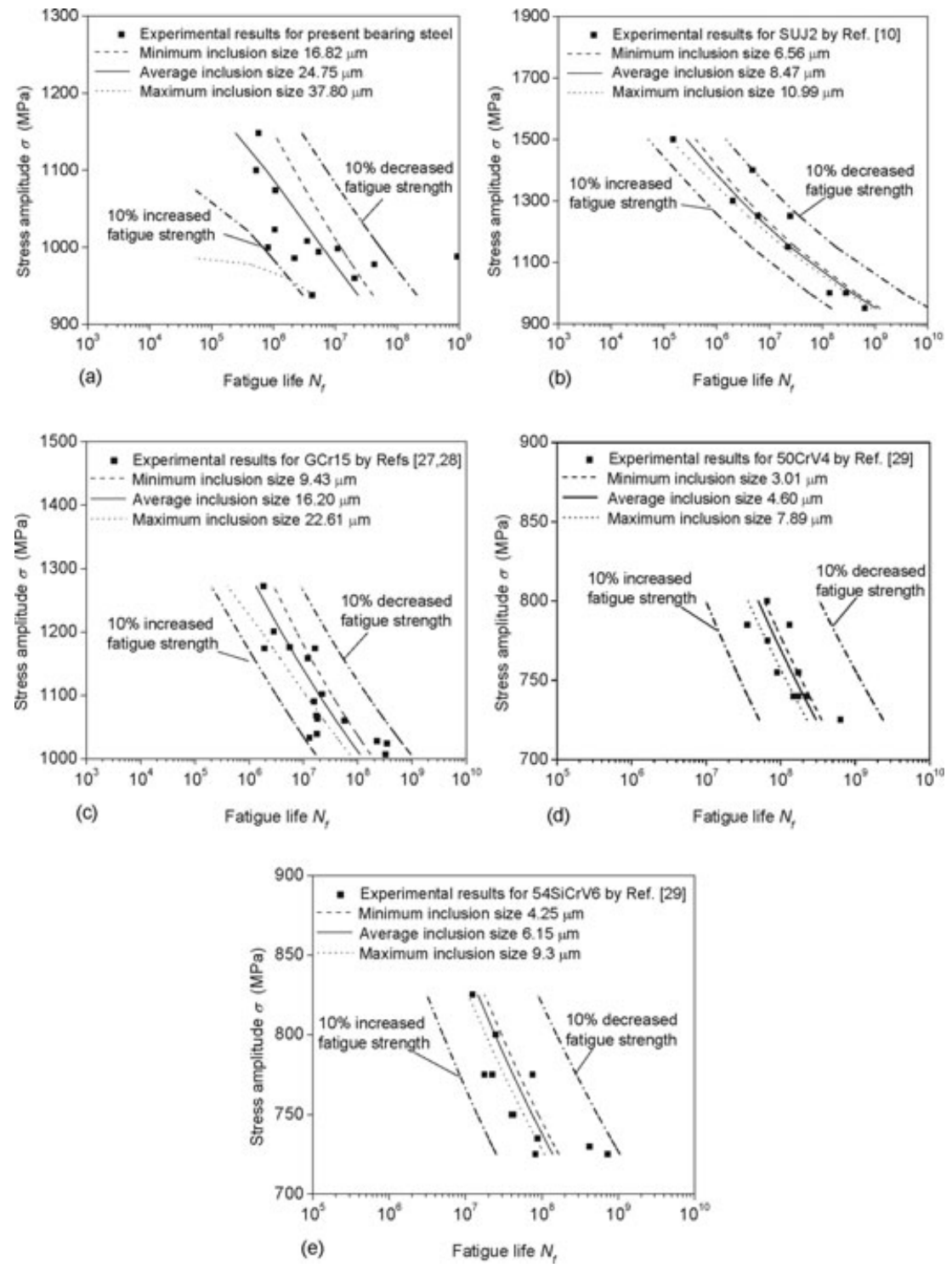

Fig. 6 Comparison of fatigue life estimation with experimental results.

scatter of inclusion size is one of the most important factors resulting in the scatter of fatigue life.

\section{CONCLUSIONS}

A model is developed for estimating the fatigue life of high-strength steels in HCF and VHCF regimes with fish-eye mode failure based on the cumulative fatigue damage in this paper. The equivalent crack growth rate is proposed, and an approximate analytical expression is derived. The model is used to estimate the fatigue life and equivalent crack growth rate for high-strength steels by assuming that the total fatigue life is spent on the formation of FGA, which accords well with the present experimental data and the results available in the literature. The paper indicates that the classical dislocation mechanism of crack propagation is not applicable for FGA, ${ }^{11}$ for the equivalent crack growth rate of FGA estimated is in the order of magnitude $10^{-14}-10^{-11} \mathrm{~m} /$ cycle which is much less than the lattice spacing $\left(\sim 10^{-10} \mathrm{~m}\right)$. It is shown that the inclusion size plays an important role in the fatigue life of high-strength steels in HCF and VHCF regimes, and that the effect of inclusion size on the fatigue life is related to the relative size of inclusion for FGA. The inclusion size has substantial influence on the fatigue life for the inclusion size close to the FGA size, whereas it has little effect on the fatigue life for the relative large value of FGA size to inclusion size. The paper also indicates that 
Table 4 Equivalent crack growth rate versus the ratio $n / N_{f}$ for the present bearing steel (GCr15), in which the subscript of $a$ denotes the specimen number

\begin{tabular}{lllllll}
\hline$n / N_{f}$ & 0 & 0.2 & 0.4 & 0.6 & 0.8 & 1.0 \\
\hline $\mathrm{d} a_{1} / \mathrm{d} n$ & $1.26 \times 10^{-11}$ & $1.29 \times 10^{-11}$ & $1.31 \times 10^{-11}$ & $1.34 \times 10^{-11}$ & $1.36 \times 10^{-11}$ \\
$\mathrm{~d} a_{2} / \mathrm{d} n$ & $6.90 \times 10^{-12}$ & $7.15 \times 10^{-12}$ & $7.42 \times 10^{-12}$ & $7.70 \times 10^{-12}$ & $7.99 \times 10^{-12}$ & $1.39 \times 10^{-11}$ \\
$\mathrm{~d} a_{3} / \mathrm{d} n$ & $4.86 \times 10^{-12}$ & $5.09 \times 10^{-12}$ & $5.34 \times 10^{-12}$ & $5.59 \times 10^{-12}$ & $5.85 \times 10^{-12}$ & $6.13 \times 10^{-12}$ \\
$\mathrm{~d} a_{4} / \mathrm{d} n$ & $2.33 \times 10^{-12}$ & $2.49 \times 10^{-12}$ & $2.66 \times 10^{-12}$ & $2.84 \times 10^{-12}$ & $3.03 \times 10^{-12}$ & $3.23 \times 10^{-12}$ \\
$\mathrm{~d} a_{5} / \mathrm{d} n$ & $1.85 \times 10^{-12}$ & $1.99 \times 10^{-12}$ & $2.13 \times 10^{-12}$ & $2.29 \times 10^{-12}$ & $2.46 \times 10^{-12}$ & $2.65 \times 10^{-12}$ \\
$\mathrm{~d} a_{6} / \mathrm{d} n$ & $1.63 \times 10^{-12}$ & $1.76 \times 10^{-12}$ & $1.89 \times 10^{-12}$ & $2.04 \times 10^{-12}$ & $2.20 \times 10^{-12}$ & $2.37 \times 10^{-12}$ \\
$\mathrm{~d} a_{7} / \mathrm{d} n$ & $1.58 \times 10^{-12}$ & $1.70 \times 10^{-12}$ & $1.84 \times 10^{-12}$ & $1.98 \times 10^{-12}$ & $2.14 \times 10^{-12}$ & $2.30 \times 10^{-12}$ \\
$\mathrm{~d} a_{8} / \mathrm{d} n$ & $1.48 \times 10^{-12}$ & $1.60 \times 10^{-12}$ & $1.73 \times 10^{-12}$ & $1.87 \times 10^{-12}$ & $2.02 \times 10^{-12}$ & $2.18 \times 10^{-12}$ \\
$\mathrm{~d} a_{9} / \mathrm{d} n$ & $1.34 \times 10^{-12}$ & $1.46 \times 10^{-12}$ & $1.58 \times 10^{-12}$ & $1.71 \times 10^{-12}$ & $1.85 \times 10^{-12}$ & $2.00 \times 10^{-12}$ \\
$\mathrm{~d} a_{10} / \mathrm{d} n$ & $1.30 \times 10^{-12}$ & $1.41 \times 10^{-12}$ & $1.53 \times 10^{-12}$ & $1.66 \times 10^{-12}$ & $1.80 \times 10^{-12}$ & $1.95 \times 10^{-12}$ \\
$\mathrm{~d} a_{11} / \mathrm{d} n$ & $1.14 \times 10^{-12}$ & $1.24 \times 10^{-12}$ & $1.35 \times 10^{-12}$ & $1.47 \times 10^{-12}$ & $1.59 \times 10^{-12}$ & $1.73 \times 10^{-12}$ \\
$\mathrm{~d} a_{12} / \mathrm{d} n$ & $8.41 \times 10^{-13}$ & $9.22 \times 10^{-13}$ & $1.01 \times 10^{-12}$ & $1.11 \times 10^{-12}$ & $1.21 \times 10^{-12}$ & $1.33 \times 10^{-12}$ \\
$\mathrm{~d} a_{13} / \mathrm{d} n$ & $5.71 \times 10^{-13}$ & $6.31 \times 10^{-13}$ & $6.98 \times 10^{-13}$ & $7.72 \times 10^{-13}$ & $8.53 \times 10^{-13}$ & $9.44 \times 10^{-13}$ \\
\hline
\end{tabular}

Table 5 Equivalent crack growth rate versus the ratio $n / N_{f}$ for SUJ2 by Ref. [10], in which the subscript of $a$ denotes the specimen number

\begin{tabular}{lllllll}
\hline$n / N_{f}$ & 0 & 0.2 & 0.4 & 0.6 & 0.8 & 1.0 \\
\hline $\mathrm{d} a_{1} / \mathrm{d} n$ & $1.6 \times 10^{-11}$ & $1.76 \times 10^{-11}$ & $1.94 \times 10^{-11}$ & $2.14 \times 10^{-11}$ & $2.35 \times 10^{-11}$ \\
$\mathrm{~d} a_{2} / \mathrm{d} n$ & $6.55 \times 10^{-12}$ & $7.41 \times 10^{-12}$ & $8.4 \times 10^{-12}$ & $9.51 \times 10^{-12}$ & $1.08 \times 10^{-11}$ & $2.59 \times 10^{-11}$ \\
$\mathrm{~d} a_{3} / \mathrm{d} n$ & $2.34 \times 10^{-12}$ & $2.73 \times 10^{-12}$ & $3.18 \times 10^{-12}$ & $3.71 \times 10^{-12}$ & $4.33 \times 10^{-12}$ & $5.05 \times 10^{-12}$ \\
$\mathrm{~d} a_{4} / \mathrm{d} n$ & $1.31 \times 10^{-12}$ & $1.55 \times 10^{-12}$ & $1.84 \times 10^{-12}$ & $2.18 \times 10^{-12}$ & $2.59 \times 10^{-12}$ & $3.07 \times 10^{-12}$ \\
$\mathrm{~d} a_{5} / \mathrm{d} n$ & $1.31 \times 10^{-12}$ & $1.55 \times 10^{-12}$ & $1.84 \times 10^{-12}$ & $2.18 \times 10^{-12}$ & $2.59 \times 10^{-12}$ & $3.07 \times 10^{-12}$ \\
$\mathrm{~d} a_{6} / \mathrm{d} n$ & $3.56 \times 10^{-13}$ & $4.36 \times 10^{-13}$ & $5.34 \times 10^{-13}$ & $6.55 \times 10^{-13}$ & $8.02 \times 10^{-13}$ & $9.83 \times 10^{-13}$ \\
$\mathrm{~d} a_{7} / \mathrm{d} n$ & $3.09 \times 10^{-14}$ & $4 \times 10^{-14}$ & $5.18 \times 10^{-14}$ & $6.71 \times 10^{-14}$ & $8.7 \times 10^{-14}$ & $1.13 \times 10^{-13}$ \\
$\mathrm{~d} a_{9} / \mathrm{d} n$ & $3.09 \times 10^{-14}$ & $4 \times 10^{-14}$ & $5.18 \times 10^{-14}$ & $6.71 \times 10^{-14}$ & $8.7 \times 10^{-14}$ & $1.13 \times 10^{-13}$ \\
$\mathrm{~d} a_{9} / \mathrm{d} n$ & $1.15 \times 10^{-14}$ & $1.52 \times 10^{-14}$ & $2.01 \times 10^{-14}$ & $2.66 \times 10^{-14}$ & $3.52 \times 10^{-14}$ & $4.65 \times 10^{-14}$ \\
\hline
\end{tabular}

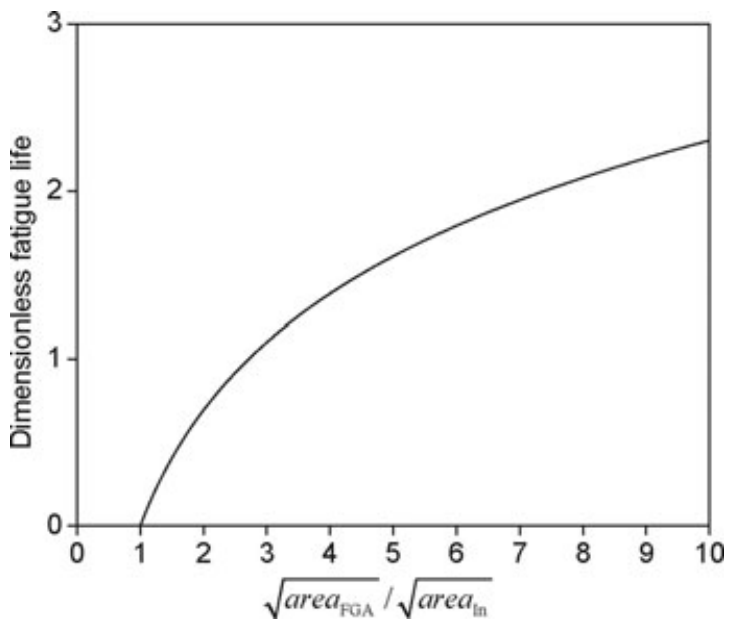

Fig. 7 Plots of the dimensionless fatigue life versus the ratio $\sqrt{\operatorname{area}_{\mathrm{FGA}}} / \sqrt{\operatorname{are} a_{\mathrm{In}}}$.

the scatter of inclusion size is one of the most important factors resulting in the scatter of fatigue life, and that decreasing the inclusion size in metallic materials can help the metal components endure longer fatigue life.

\section{Acknowledgement}

The authors gratefully acknowledge the support of the National Natural Science Foundations of China (grant no 10721202 and 11172304).

\section{REFERENCES}

1 Wang, Q. Y., Berard, J. Y., Dubarre, A., Baudry, G., Rathery, S. and Bathias, C. (1999) Gigacycle fatigue of ferrous alloys. Fatigue Fract. Eng. Mater. Struct. 22, 667-672.

2 Bathias, C., Drouillac, L. and Le Francois, P. (2001) How and why the fatigue $S-N$ curve does not approach a horizontal asymptote. Int. F. Fatigue 23, S143-S151.

3 Paris, P. C., Marines-Garcia, I., Hertzberg, R. W. and Donald, J. K. (2004) The relationship of effective stress intensity, elastic modulus and Burgers vector on fatigue crack growth as associated with "fish-eye" gigacycle phenomena. In: Proceedings of the Third International Conference on Very High-Cycle Fatigue (Edited by T. Sakai and Y. Ochi). The Society of Materials Science, Kyoto, pp. 1-13.

4 Hong, Y., Zhao, A. and Qian, G. (2009) Essential characteristic and influential factors for very-high-cycle fatigue behavior of metallic materials. Acta Metall. Sinica 45, 769780 . 
5 Plumtree, A. and Untermann, N. (2010) Long fatigue life critical crack lengths. Fatigue Fract. Eng. Mater. Struct. 33, 320-330.

6 Qian, G., Zhou, C. and Hong, Y. (2011) Experimental and theoretical investigation of environmental media on very-high-cycle fatigue behavior for a structural steel. Acta Mater. 59, 1321-1327.

7 Marines, I., Bin, X. and Bathias, C. (2003) An understanding of very high cycle fatigue of metals. Int. F. Fatigue 25, 1101-1107.

8 Sakai, T. (2009) Review and prospects for current studies on very high cycle fatigue of metallic materials for machine structural use. 7. Mech. Mater. Eng. 3, 425-439.

9 Murakami, Y., Nomoto, T. and Ueda, T. (1999) Factors influencing the mechanism of superlong fatigue failure in steels. Fatigue Fract. Eng. Mater. Struct. 22, 581-590.

10 Shiozawa, K., Lu, L. and Ishihara, S. (2001) $S-N$ curve characteristics and subsurface crack initiation behaviour in ultra-long life fatigue of a high carbon-chromium bearing steel. Fatigue Fract. Eng. Mater. Struct. 24, 781-790.

11 Tanaka, K. and Akiniwa, Y. (2002) Fatigue crack propagation behaviour derived from $S-N$ data in very high cycle regime. Fatigue Fract. Eng. Mater. Struct. 25, 775-784.

12 Murakami, Y., Nomoto, T. and Ueda, T. (2000) On the mechanism of fatigue failure in the superlong life regime ( $N>10^{7}$ cycles). Part I: influence of hydrogen trapped by inclusions. Fatigue Fract. Eng. Mater. Struct. 23, $893-$ 902.

13 Shiozawa, K., Morii, Y., Nishino, S. and Lu, L. (2006) Subsurface crack initiation and propagation mechanism in high strength steel in a very high cycle fatigue regime. Int. 7 . Fatigue 28, 1521-1532.

14 Murakami, Y. and Endo, M. (1994) Effects of defects, inclusions and inhomogeneities on fatigue strength. Int. $\mathcal{F}$. Fatigue 16, 163-182.

15 Wang, Q. Y., Bathias, C., Kawagoishi, N. and Chen, Q. (2002) Effect of inclusion on subsurface crack initiation and gigacycle fatigue strength. Int. F. Fatigue 24, 1269-1274.

16 Tanaka, K. and Mura, T. (1981) A dislocation model for fatigue crack initiation. F. Appl. Mech. 48, 97-103.

17 Chapetti, M. D., Tagawa, T. and Miyata, T. (2003) Ultra-long cycle fatigue of high-strength carbon steels part II: Estimation of fatigue limit for failure from internal inclusions. Mater. Sci. Eng. A 356, 236-244.

18 Harlow, D. G., Wei, R. P., Sakai, T. and Oguma, N. (2006)
Crack growth based probability modeling of $S-N$ response for high strength steel. Int. F. Fatigue 28, 1479-1485.

19 Liu, Y. B., Yang, Z. G., Li, Y. D., Chen, S. M., Li, S. X., Hui, W. J. (2009) Dependence of fatigue strength on inclusion size for high-strength steels in very high cycle fatigue regime. Mater. Sci. Eng. A 517, 180-184.

20 Liu, Y. B., Li, Y. D., Li, S. X., Yang, Z. G., Chen, S. M., Hui, W. J. (2010) Prediction of the $S-N$ curves of high-strength steels in the very high cycle fatigue regime. Int. F. Fatigue 32, 1351-1357.

21 Chapetti, M. D., Tagawa, T. and Miyata, T. (2003) Ultra-long cycle fatigue of high-strength carbon steels part I: Review and analysis of the mechanism of failure. Mater. Sci. Eng. A 356, 227-235.

22 Wagner, D., Ranc, N., Bathias, C. and Paris, P. C. (2010) Fatigue crack initiation detection by an infrared thermography method. Fatigue Fract. Eng. Mater. Struct. 33, 12-21.

23 Cui, W. C. (2002) A state-of-the-art review on fatigue life prediction methods for metal structures. 7. Mar. Sci. Technol. 7, 43-56.

24 Murakami, Y., Kodama, S. and Konuma, S. (1988) Quantitative evaluation of effects of nonmetallic inclusions on fatigue strength of high strength steel. Trans. 7SME 54A, 688-695.

25 Sakai, T., Sato, Y., Nagano, Y., Takeda, M. and Oguma, N. (2006) Effect of stress ratio on long life fatigue behavior of high carbon chromium bearing steel under axial loading. Int. 7. Fatigue 28, 1547-1554.

26 Li, W., Sakai, T., Li, Q., Lu, L. T. and Wang, P. (2010) Reliability evaluation on very high cycle fatigue property of GCr15 bearing steel. Int. F. Fatigue 32, 1096-1107.

27 Zhou, C. and Hong, Y. (2004) Experimental investigation on very-high-cycle fatigue of GCr15 steel. 7. Mech. Strength 26, $157-160$.

28 Zhou, C. (2005) Experimental studies and analyses on very-high-cycle fatigue behavior of GCr15 bearing steel. Ph.D. Dissertation, Institute of Mechanics, Chinese Academy of Science, Beijing (in Chinese).

29 Yang, Z. G., Li, S. X., Liu, Y. B., Li, Y. D., Li, G. Y., Hui, W. J. (2008) Estimation of the size of GBF area on fracture surface for high strength steels in very high cycle fatigue regime. Int. F. Fatigue 30, 1016-1023.

30 Taylor, D. (1989) Fatigue Thresholds. Butterworth \& Co. Ltd, pp. 131-157. 